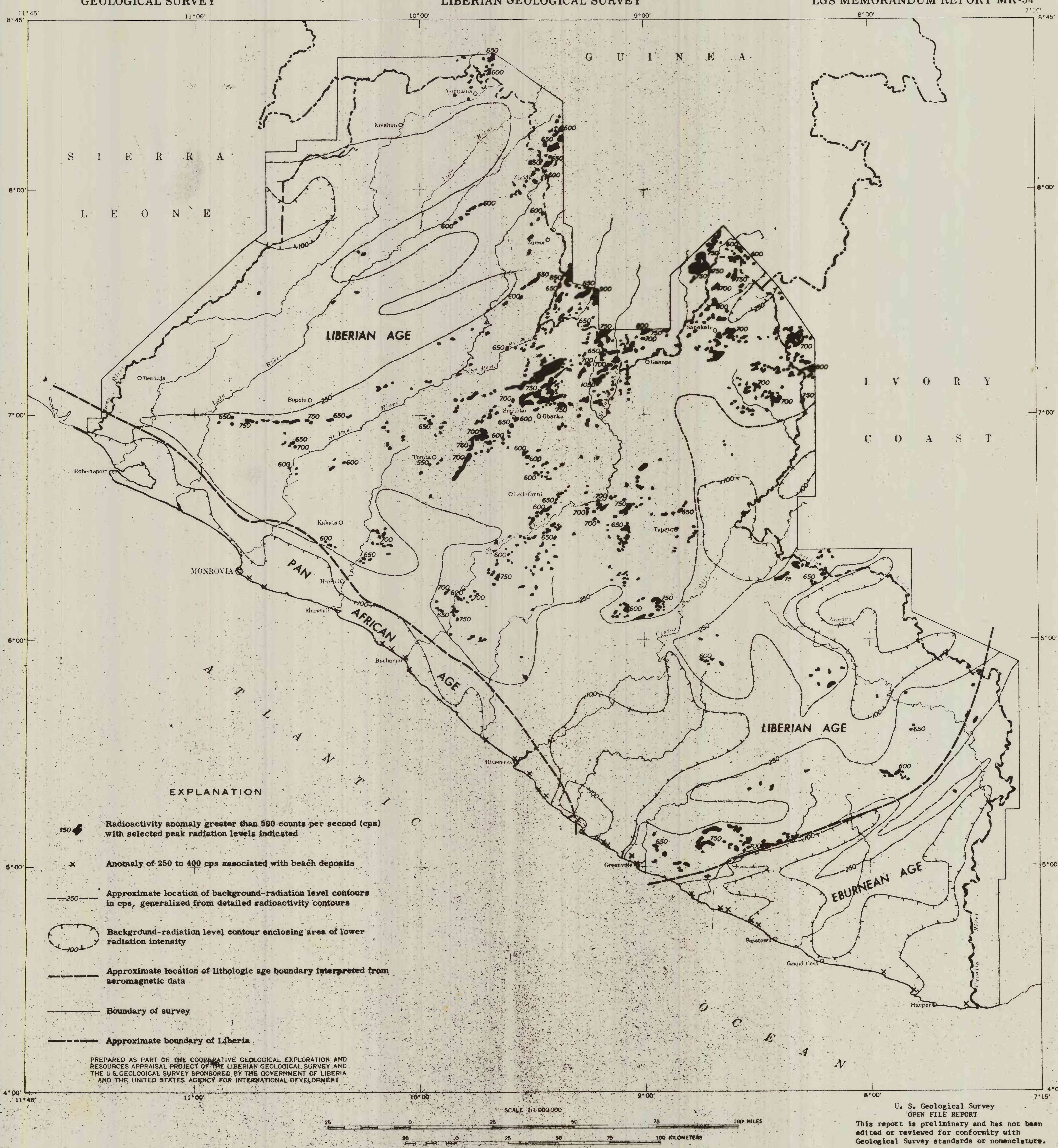

\title{
HIGH-AMPLITUDE RADIOACTIVITY ANOMALIES IN LIBERIA
}

John C. Behrendt, U.S. Geological Survey and Cletus $\$$, Wotorson, Liberian Geological Survey

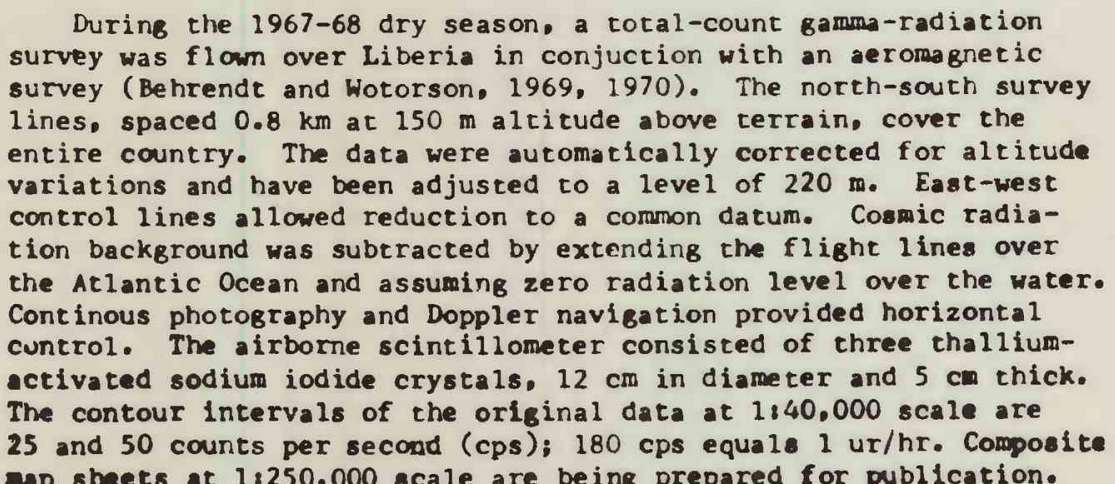

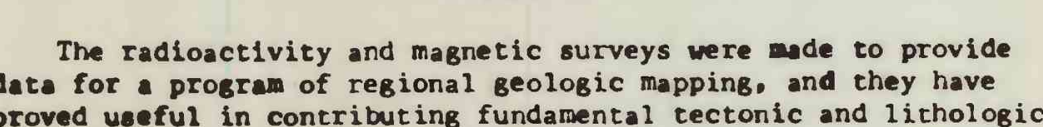

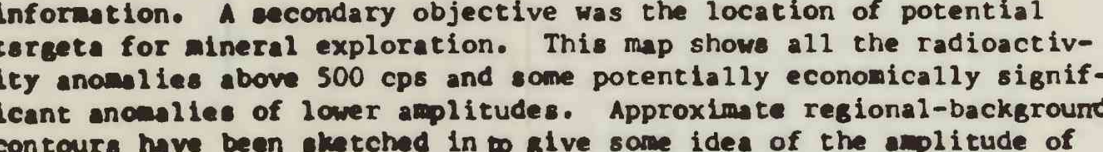

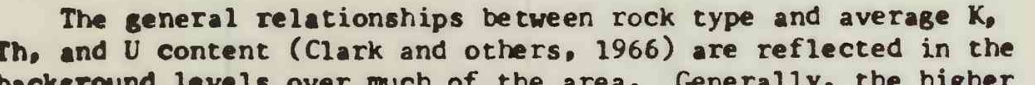

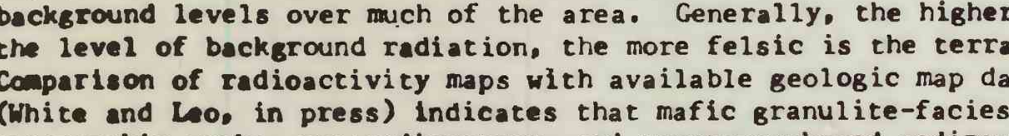

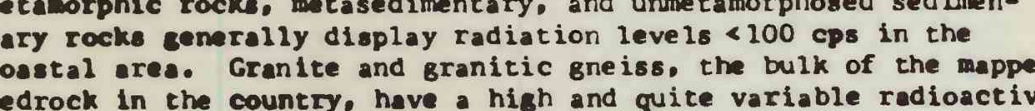

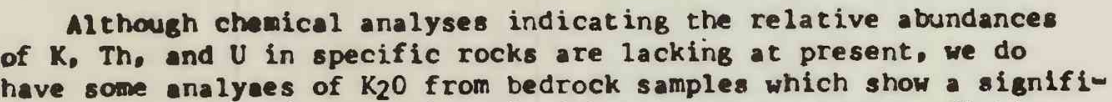
$\begin{array}{ll} & \\ & \end{array}$

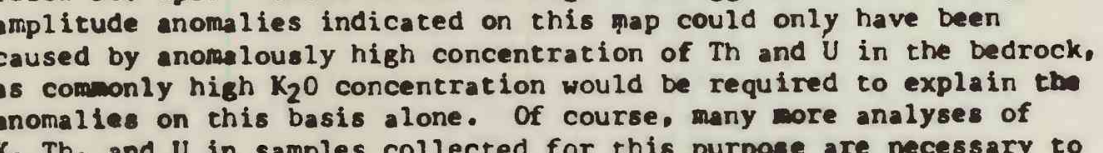

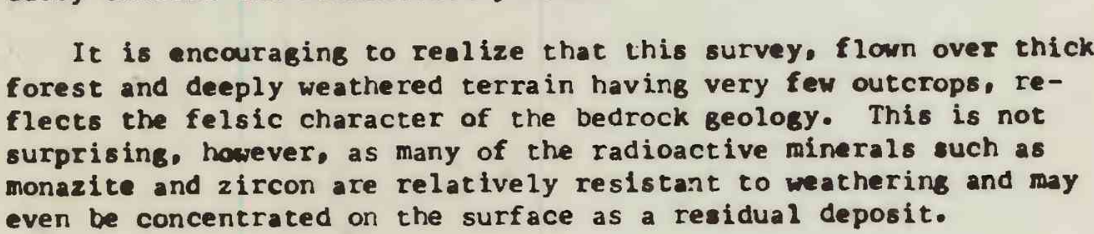

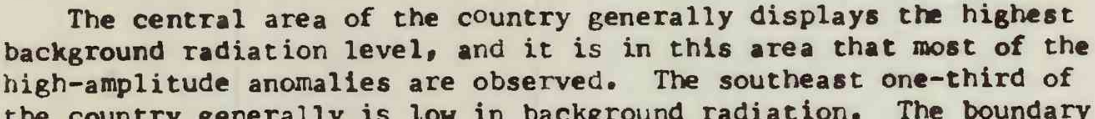

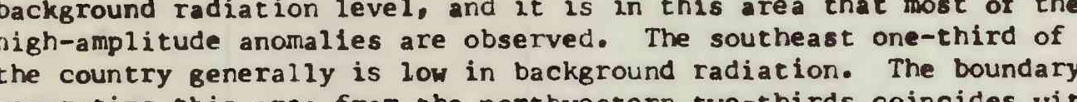

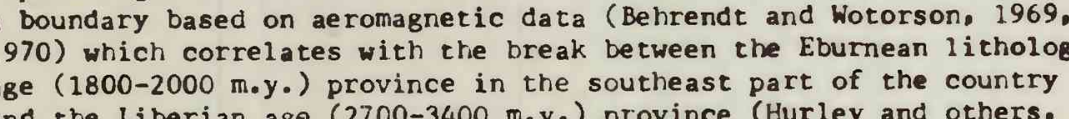

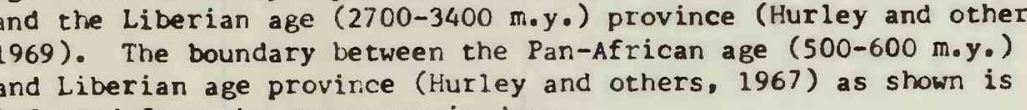

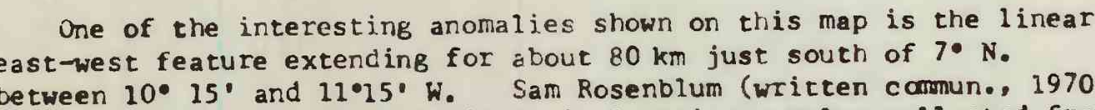

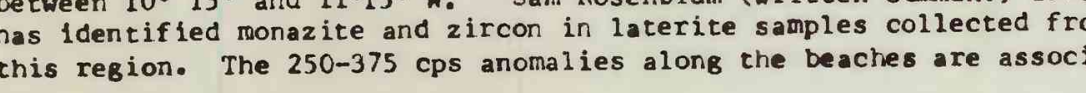

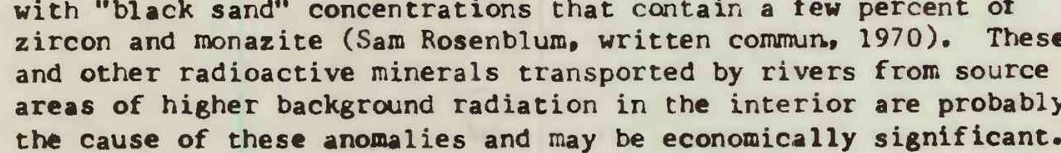
ond

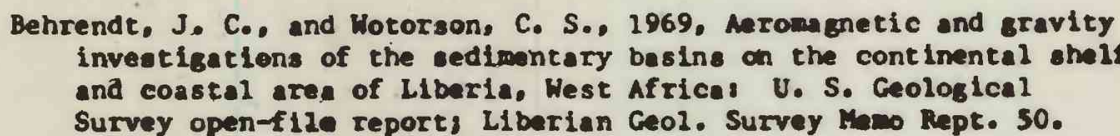
and

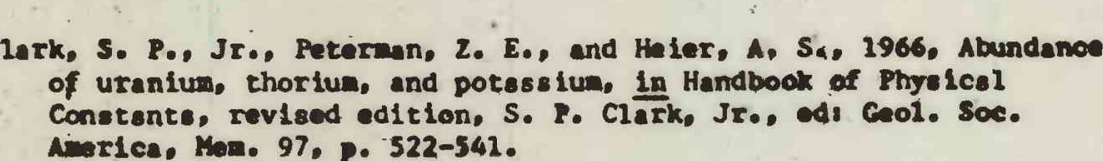

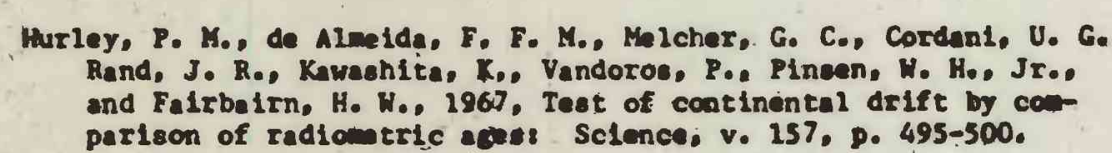

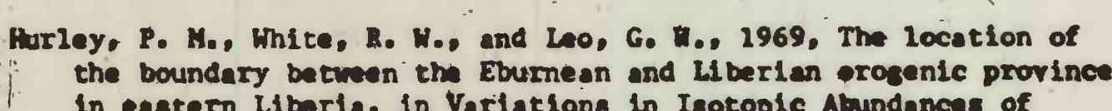

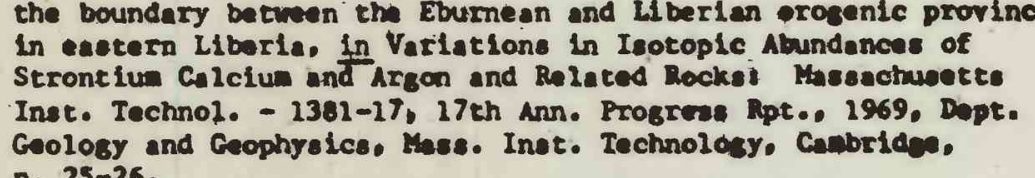

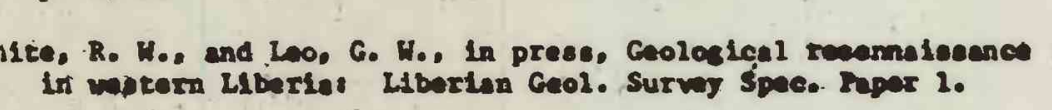

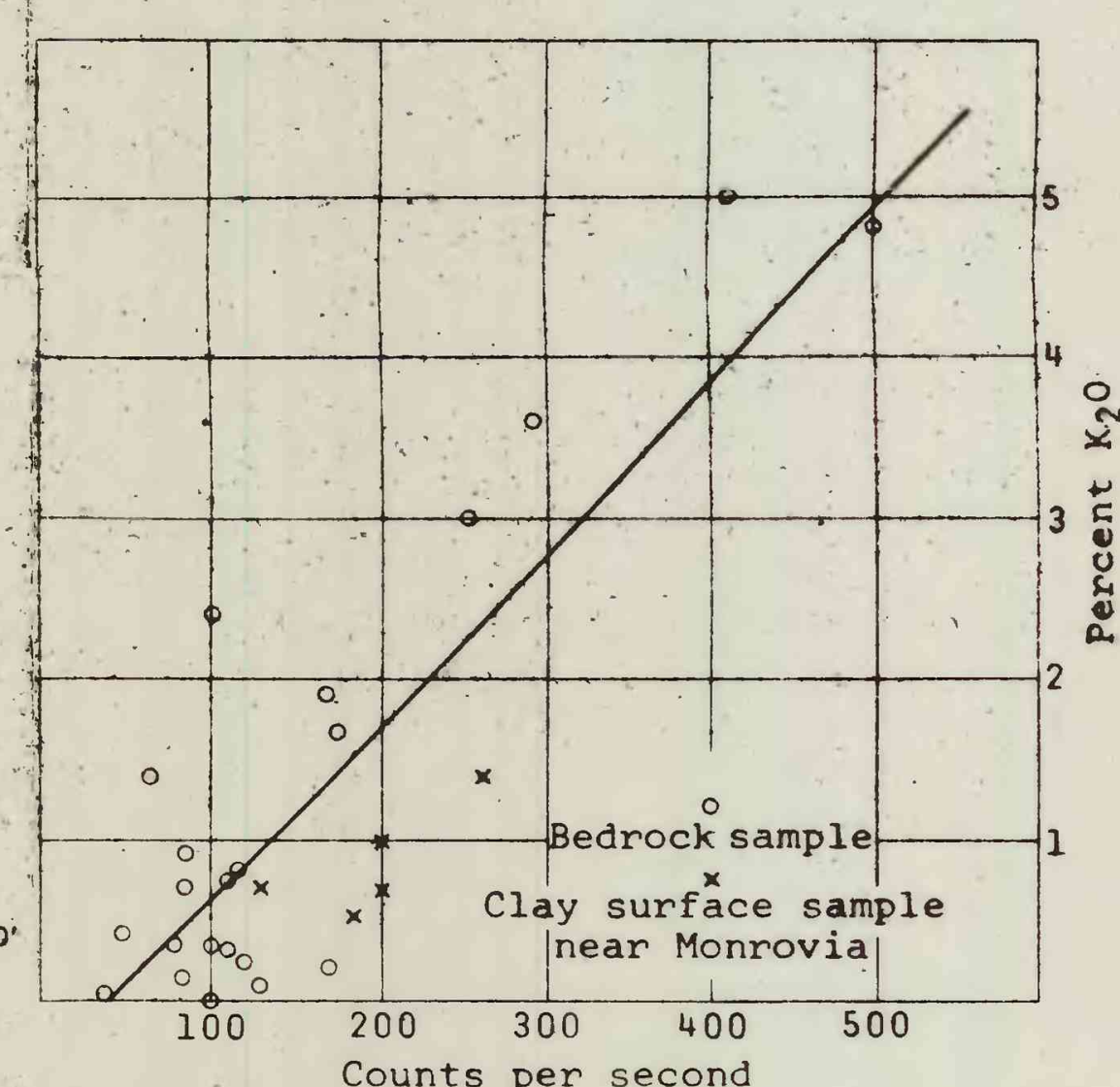

Figure 1.-Peircent $\mathrm{K}_{2} \mathrm{O}$ from rock. (or ma count observed. The least-square
straight line fitted to the data is $K_{2}=-.44+.0108 \mathrm{R}$, where $\mathrm{R}$ is
total gamma count. Standard devia

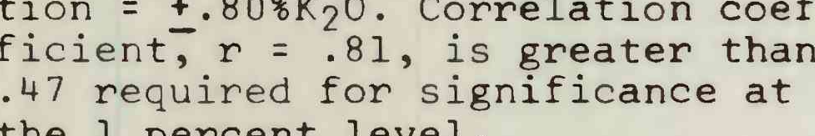

